DOI: http://dx.doi.org/10.5007/1980-3532.2015n13p13

\title{
Pesquisa de campo sobre Ensino de Ciências Sociais: alguns desafios metodológicos
}

\section{Field Research about Teaching Social Sciences: some methodological challenges}

\author{
Amurabi Oliveira \\ Doutor em Sociologia (UFPE) \\ Professor do Programa de Pós-Graduação em Sociologia Política (UFSC) \\ amurabi_cs@hotmail.com \\ Vanessa Rego Ferreira \\ Mestra em Educação (UFAL) \\ Professora de Sociologia (SEE/AL) \\ vanessadorego@hotmail.com \\ Beatriz Demboski Búrigo \\ Graduanda do Curso de Ciências Sociais (UFSC) \\ Bolsista PIBIC \\ beademboskiburigo@hotmail.com \\ Felipe Boin \\ Graduando do Curso de Ciências Sociais (UFSC) \\ Bolsista PIBIC \\ fbboutin@gmail.com
}

\section{Resumo}

Este trabalho busca analisar os desafios encontrados ao realizar pesquisas em campo na área do Ensino de Sociologia, o que será realizado por meio de um breve balanço acerca da utilização de tal recurso nas pesquisas realizadas em nível de pós-graduação sobre esse tema, e na apresentação das dificuldades encontradas para a realização do trabalho de campo em duas diferentes pesquisas que envolvem o Ensino de Sociologia. Propõe-se aqui a discussão das dificuldades de acesso e de desenvolvimento dessas pesquisas junto às esferas de Secretarias de Educação, às escolas e aos professores da educação básica. Palavras-chave: Ensino de Sociologia; Sociologia da Educação; Antropologia da Educação; Etnografia da prática escolar.

\begin{abstract}
This paper analyzes the challenges to conduct research in the field in Teaching Sociology area, which will be held by a brief assessment on the use of this resource in research carried out at the level of postgraduate on this subject, and presentation of the difficulties in conducting field work in two different research involving the teaching Sociology. It is proposed here to discuss the difficulties of access and development of these surveys to the spheres of Secretariats of Education, schools and basic education teachers.
\end{abstract}

Keywords: Teaching Sociology; Sociology of Education; Anthropology of Education; Ethnography of school practice.

Originais recebidos em: 10/03/2015

Aceito para publicação em: 20/05/2016

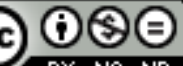

Comercial-Vedada a criação de obras derivadas 3.0 Unported License.

Revista Em Debate (UFSC), Florianópolis, volume 13, p. 13-29, 2015. ISSNe 1980-3532 


\section{Introdução}

A área do Ensino de Sociologia no Brasil encontra-se em processo de consolidação, ainda que tenha havido significativos avanços nos últimos anos (OLIVEIRA, 2015b). Em balanços recentemente realizados, que analisam sobretudo a produção desenvolvida junto aos Programas de Pós-Graduação, há um claro indicativo de que tem ocorrido um incremento substancial nessa área, marcado por um predomínio das pesquisas realizadas junto a programas de educação, mas com uma crescente participação dos programas de ciências sociais (CAREGNATO, CORDEIRO, 2014; HANDFAS, MAÇAIRA, 2014). Tais balanços têm se ocupado predominantemente em apontar as tendências que vem se desenhando no campo, e também de indicar as temáticas que tem predominado na agenda de pesquisa que começa a se delinear.

Apesar da contínua reflexão que a incipiente comunidade de pesquisadores sobre o tema tem desenvolvido, pouca atenção tem sido dada a uma análise um pouco mais detalhada aos procedimentos metodológicos assumidos nos trabalhos realizados até então. Esta questão torna-se especialmente relevante considerando a ampliação do número de programas de pós-graduação, o crescente interesse pelo tema, bem como o advento de iniciativas recentes como a criação da linha de pesquisa sobre "Ensino de Sociologia" junto ao Programa de Pós-Graduação em Ciências Sociais da Universidade Estadual de Londrina (UEL), e do Mestrado Profissional em Ciências Sociais para o Ensino Médio junto à Fundação Joaquim Nabuco (FUNDAJ) ${ }^{1}$.

Mais que um balanço sobre os procedimentos metodológicos adotados pelas investigações na área de Ensino de Sociologia, nos focaremos neste artigo em indicar os desafios encontrados para o desenvolvimento de pesquisas de campo nessa seara. Para tal finalidade tomaremos como fio condutor a exposição dos desafios encontrados para o desenvolvimento de duas distintas pesquisas nessa área: a primeira é uma já concluída que versou sobre o ensino de sociologia na reforma curricular realizada no Estado de Alagoas $^{2}$, e a segunda encontra-se em curso e se volta para as disposições sociais dos professores de sociologia em Florianópolis ${ }^{3}$.

No primeiro caso a pesquisa foi realizada entre outubro de 2013 e setembro de 2014, cujas entrevistas foram realizadas junto à gerente da GEORC; ao consultor da área de Sociologia49; ao coordenador da componente curricular de Sociologia (que

1 Atualmente está em curso a criação de um mestrado profissional voltado para o Ensino de Ciências Sociais em rede envolvendo diversas instituições do país.

2 Pesquisa financiada pela Fundação de Amparo à Pesquisa do Estado de Alagoas (FAPEAL).

3 Pesquisa financiada pelo Conselho Nacional de Desenvolvimento Científico e Tecnológico (CNPq). 
também é professor de Sociologia na SEE/AL)50; e, por fim junto a três professores de Sociologia que atuam na rede. E os principais documentos analisados foram os referenciais curriculares existentes até então, e o novo documento produzido. Na segunda, foram realizadas entrevistas com quatro professores de distintas escolas, e atualmente estamos acompanhando as aulas de dois deles, este é um trabalho que vem sendo realizado desde março de 2016.

Em ambos os casos tratam-se de pesquisas que envolvem trabalho de campo e prática etnográfica ${ }^{4}$. Nesse momento, dado os limites desse artigo, focaremos com mais ênfase nas dificuldades de acesso e de desenvolvimento de pesquisa junto a diferentes esferas, envolvendo as Secretarias de Educação, escolas e professores, considerando que em cada caso há particularidades encontradas, bem como potencialidades que puderam ser exploradas pelas investigações realizadas. Todavia, para uma melhor compreensão das questões aqui postas começaremos com uma reflexão mais ampla sobre a pesquisa sobre Ensino de Sociologia no Brasil.

\section{O Ensino de Sociologia como um campo de pesquisa}

Como já fora apontado, voltamo-nos aqui para um campo que está em amplo processo de expansão de consolidação, mas que ainda demanda reflexões mais apuradas. Se considerarmos de forma mais ampla que essas pesquisas poderiam estar sob a rubrica da Sociologia da Educação - SE, considerada aqui de forma $\operatorname{ampliada}^{5}$, e que devido à estrutura acadêmica brasileira encontra-se dispersa, tanto junto às Faculdades de Educação, quanto aos Departamentos de Ciências Sociais/Sociologia, ainda que possamos problematizar a autoafirmação de determinados grupos de pesquisa enquanto pertencentes ao campo das SE, como podemos verificar através do exame realizado por Oliveira e Silva (2014).

Não podemos olvidar nesse ponto que o processo de apropriação dos referenciais teóricos e metodológicos do campo das Ciências Sociais pela Educação não ocorre sem dissonâncias, e como indica o balanço realizado por Martins e Weber (2010), esse processo implica no desenvolvimento de pesquisas por vezes frágeis em termos metodológicos. Nessa mesma direção, Valente (1996), questiona a incorporação da

\footnotetext{
4 Para uma melhor análise acerca da prática etnográfica vide Beaud \& Weber (2007).

5 Compreende-se aqui a SE desenvolvida numa interface mais ampla com o campo das Ciências Sociais, dialogando também com a Antropologia e Ciência Política, bem como com outras Ciências Humanas.
} 
etnografia pelo campo da Educação sem que haja a devida articulação entre os procedimentos metodológicos e as matrizes de pensamento nas quais estes foram forjados, de modo que não haveria como reduzir a etnografia a uma simples "técnica de coleta de dados".

Não se trata aqui de desmerecer as pesquisas realizadas junto a Programas de Pós-Graduação em Educação nesta seara, pelo contrário, já que a estas constituem a maior parte do escopo existente, todavia, é necessário que os que questionamentos metodológicos surjam de forma articulada com uma compreensão mais ampla acerca das tensões que emergem no próprio campo, ainda que não seja possível aprofundar aqui tais questões ${ }^{6}$.

Utilizando como banco de dados as teses e dissertações existentes no Laboratório de Ensino Florestan Fernandes (LABES) ${ }^{7}$, que conta atualmente com 48 dissertações e 11 teses de doutorado disponíveis para consulta, podemos observar algumas tendências em termos de opções metodológicas adotadas pelos pesquisadores na área.

De forma geral podemos afirmar que são pesquisas de caráter qualitativo, havendo uma parca utilização de dados secundários que possibilitem generalizações mais amplas acerca do cenário no qual se insere o Ensino de Sociologia. Os recortes tendem a privilegiar estudos de caso, ainda que recorrentemente não seja posto nestes termos, bem como determinadas temporalidades, com destaque para o processo de institucionalização da Sociologia no currículo escolar.

As análises utilizando fontes históricas são relativamente poucas, sendo mais comum o acionamento da análise documental, incluindo aí a legislação que tangencia o tema, bem como a referência a outras pesquisas já realizadas. Também ganha destaque a análise de manuais e livros didáticos, pode-se acreditar que tendencialmente essas pesquisas devem ganhar ainda mais visibilidade com o incremento que tem havido na produção de livros didáticos de Sociologia (CIGALES, OLIVEIRA, 2015), o que reflete a própria introdução dessa disciplina no Plano Nacional do Livro Didático (PNLD).

Interessante perceber que este campo também é bastante autoreferido, alguns trabalhos como os de Meucci (2000) e Santos (2002) tornaram-se praticamente

6 Para um exame mais cuidadoso acerca da SE no Brasil vide Neves (2002), Martins e Weber (2010), Oliveira e Silva \(2014).

7 O Laboratório é mantido pela Faculdade de Educação da Universidade Federal do Rio de Janeiro (UFRJ) e coordenado pelas professoras Anita Handfas e Julia Polessa Maçaira, tendo se tornado uma importante fonte de pesquisa para os investigadores da área. Endereço para consulta: www.labes.fe.ufrj.br 
referências obrigatórias às demais teses e dissertações, especialmente quando retomam o histórico intermitente da disciplina no currículo escolar, ainda que isso implique também na reprodução dos limites existentes nesses trabalhos, bem como de alguns equívocos (OLIVEIRA, 2015b). Takagi (2013) critica a incisiva repetição nestes trabalhos do histórico de institucionalização da disciplina, para a autora isso pode indicar tanto um desconhecimento da literatura mais ampla sobre o tema, como também a necessidade de afirmação e legitimação dessa temática no campo acadêmico.

Também já fora objeto de crítica por parte de Moraes (2011) o tom engajado que marca predominantemente essa literatura, em nossa compreensão isso pode ser explicado pelo próprio habitus dos pesquisadores que se voltam para a temática, que em sua maioria são professores de Sociologia que já atuam ou atuaram na Educação Básica, egressos das licenciaturas em Ciências Sociais, ou ainda professores que atuam na formação de professores da área. Obviamente que o tom engajado que possamos encontrar por vezes reflete o lugar a partir do qual os sujeitos produzem suas visões de mundo, e sendo esta uma visão que Bourdieu (2004) denomina de autóctone não podemos olvidar que "O interesse ligado ao fato de se pertencer a um campo está associado a uma forma de conhecimento prático, interessada, que aquele que não faz parte do campo não possui." (Idem, p. 110).

Voltando-nos mais atentamente à dimensão metodológica, podemos observar que o instrumento de coleta de dados preferencialmente utilizado é a entrevista, sendo utilizada principalmente com pequenos grupos. Os sujeitos de pesquisa recorrentes no escopo analisado são os professores que atuam nas escolas lecionando Sociologia, possuindo ou não formação na área de Ciências Sociais.

Poucos trabalhos articulam os dados de pesquisa obtidos com as entrevistas à observações in loco da prática dos professores, de modo que a compreensão dos pesquisadores acerca de como se operacionaliza a Sociologia na escola parte exclusivamente, na maior parte dos casos, do que é posto pelas narrativas dos docentes.

Nesta direção, parece-nos que as lições magistrais deixadas por R. C. Oliveira (2006) acerca do ver, ouvir e escrever podem nos servir de base para pensarmos nos limites impostos por tais opções metodológicas, considerando a complementaridade existente nesses momentos do trabalho de campo. Não se pode olvidar ainda que o próprio trabalho de campo é também um treinamento do olhar, e que essas atividades encontram-se previamente comprometidas com os horizontes das Ciências Sociais, estão sintonizados com o sistema de ideia e de valores próprios desse campo disciplinar. 
Ainda confluindo com essa crítica, não podemos deixar de lado as ponderações realizadas por Woods (1999, p. 144-145) ao indicar que "Um etnógrafo é sua principal fonte de dados, sendo uma testemunha ocular do acontecimento (SMITH et al, 1988). Não estando presente quando o acontecimento ocorreu significa não viver o processo enquanto ele surge e se desenrola, e a investigação perde a força da triangulação (nos relatos dos outros) das nossas próprias observações."

Não se trata aqui de desenvolver um argumento que privilegie apenas a etnografia como forma de pesquisa nessa área, porém busca-se aqui ressaltar o caráter afirmativo da pesquisa etnográfica no campo educacional (OLIVEIRA, 2013; GUSMÃO, 2014), indicando também a potencialidade de seu uso para a superação de determinados limites encontrados nas pesquisas sobre Ensino de Sociologia, em que pese o fato de que recorrentemente não há uma exposição clara dos procedimentos metodológicos adotados.

Ora, como nos indica Sarmento (2011, p. 156) há atividades centrais na investigação etnográfica em escolas: “(...) a observação participante das práticas cotidianas nas escolas, as entrevistas aos alunos, aos (às) professores (as) e outros membros das comunidades educativas, e a análise de conteúdo do conjunto de documentos produzidos pela escola.". Ao que nos parece, as pesquisas sobre Ensino de Sociologia voltam-se predominantemente para os dois últimos pontos, deixando num segundo plano a observação do cotidiano escolar, no qual o ensino dessa ciência de fato se efetiva.

Dentro da análise realizada pode-se afirmar claramente que a etnografia não é a ferramenta mais recorrente em termos metodológicos nas pesquisas sobre Ensino de Sociologia, o que pode ser explicado talvez pelas dificuldades existentes na produção de diálogos entre a Antropologia e a Educação, e pelo lugar periférico que a Educação ocupa na agenda de pesquisa da Antropologia brasileira (OLIVEIRA, 2015a), em que pese a criação, ainda em 2006, da Comissão de Ensino de Antropologia junto à Associação Brasileira de Antropologia (ABA), posteriormente transformada em comissão de Educação, Ciência e Tecnologia ${ }^{8}$. Um dado que reafirma o argumento elaborado aqui é o fato de que apenas o trabalho de Schweig (2015), dentre os

8 Tal comissão tem se inserido dentro de debates mais amplos envolvendo a questão do Ensino de Antropologia, sobretudo sobre o ensino em nível superior, com especial atenção para as graduações em Antropologia que têm surgido recentemente. 
disponíveis no LABES, foi realizado junto a um Programa de Pós-Graduação em Antropologia.

Se nos trabalhos sobre a temática não há predominantemente o uso da etnografia, ou mesmo de um trabalho de campo mais incisivo que adentre o espaço escola e investigue de perto as práticas pedagógicas no Ensino de Sociologia, como podemos pensar os desafios postos nesse tipo de investigação? Tomaremos a partir daqui como fio condutor duas pesquisas que se propuseram a realizar trabalho de campo envolvendo o Ensino de Sociologia, ainda que a partir de diferentes vieses.

\section{Pesquisando a Reforma Curricular do Ensino de Sociologia}

Esta pesquisa inicialmente não seria sobre a reforma curricular do Ensino de Sociologia em Alagoas, mas sim como que os professores elaboram seus próprios currículos em suas práticas cotidianas, entretanto, quando o trabalho de campo estava por se iniciar começou o processo de reforma do currículo da Educação Básica de Alagoas, que já contava com seus referenciais, incluindo os de Sociologia, mas que nesse momento passava por alterações profundas, de modo que a pesquisa foi redirecionada para esse processo.

A opção pela etnografia levou-nos a realização do trabalho de campo durante três momentos distintos desse processo: 1) a construção dos Referenciais Curriculares de Sociologia; 2) a elaboração e debate dos referenciais da área de Ciências Humanas; 3) a estruturação das orientações didático metodológicas.

A opção pela etnografia trouxe ganhos para a pesquisa na medida em que possibilitou uma profícua reflexão sobre a relação entre os professores e as políticas implementadas pela Secretaria do Estado da Educação e do Esporte de Alagoas (SEE/AL), e de como essa relação afeta a prática dos docentes. Todavia, não podemos deixar de lado o fato de que o fazer etnográfico não ocorre sem sobressaltos, a entrada em campo nesse caso apesar de ter sido facilitada pelo fato de que um dos professores do programa de pós-graduação junto ao qual realizamos a pesquisa conhecia o coordenador da empresa contratada para conduzir a reforma, tendo passado seu contato, alguns dados importantes para a pesquisa foram de fato de difícil acesso.

A Sociologia em Alagoas, como apontam Oliveira et al. (2014) foi reintroduzida no currículo escolar a partir do começo dos anos 2000, o que fora reforçado pela 
presença da disciplina através do Processo Seletivo Seriado (PSS), que garantia o acesso à Universidade Federal de Alagoas (UFAL). Entretanto, junto à Secretaria de Educação não foi possível localizar a documentação referente ao processo de institucionalização desta disciplina no currículo escolar.

Esta dificuldade inicial em grande medida era explicada pelos sujeitos da pesquisa, isso devido às descontinuidades existentes nas equipes que compõem a burocracia da Secretaria de Educação, tendo em vista que a cada novo governo a equipe era sempre modificada. Este cenário, ainda que afete às pesquisas educacionais de forma bastante ampla, tem um impacto ainda mais significativo no caso da Sociologia, tendo em vista que é uma disciplina cuja história recente nos diversos contextos locais ainda pouco conhecemos.

Outras intempéries em campo se deram devido à dificuldade em acessar a todas reuniões, bem como ao cancelamento de algumas durante as quais parte da pesquisa seria realizada. Chamamos a atenção ainda para fato de que os diversos agentes envolvidos possuíam conhecimentos distintos acerca do processo, pois tanto estávamos lidando com os profissionais da empresa contratada por meio de Pregão Eletrônico para conduzir o processo, com aqueles que compõem a burocracia da Secretaria de Educação e com os docentes. Nesse ponto as observações realizadas por Barth (2000) acerca do caráter distributivo da cultura nas sociedades complexas mostra-se de suma relevância para o trabalho de campo em educação, pois mesmo as práticas pedagógicas dos professores em sala de aula são permeadas pelas diversas concepções de ensino existente entre esses múltiplos agentes, sendo assim, ainda que o foco recaísse sobre o Ensino de Sociologia nossa pesquisa também envolveu outros agentes, cujas ações em nossa compreensão também possuíam impacto direto sobre a realidade a qual nos interessa investigar.

O Referencial Curricular para a Educação Básica do Estado de Alagoas teve um processo de construção que se iniciou ainda em 2011, porém a publicação do material ocorrera apenas no ano de 2014, havendo claramente uma acentuada disputa em relação ao conhecimento, visões de mundo, concepções teóricas e pedagógicas que estariam presentes na versão final (FERREIRA, 2015).

No caso da nossa pesquisa salientamos algumas questões peculiares ao processo de construção dos referenciais. A primeira dela concatena-se à descontinuidade no processo de construção do Referencial, no que concerne a equipe técnica que conduziu o processo desde o início. O processo era conduzido de acordo com a gestão presente, 
ou seja, cada gestor conduzia a proposta mediante suas perspectivas prontamente legitimadas pelos demais técnicos da SEE/AL. Todo o processo envolveu ao menos duas diferentes gestões, a primeira de 2011 até 2012 e a segunda de 2012 a 2014.

Segundo a agente que coordenou o processo durante a nossa pesquisa, a gestão anterior $^{9}$ não promovia os encaminhamentos necessários ao processo, retardando-o consequentemente. Este é outro ponto que merece ser problematizado durante a realização do trabalho de campo, pois os agentes possuem também interesses a partir de seu lugar de fala, de modo que o pesquisador deve articular de maneira contínua o que é enunciado pelos sujeitos de pesquisa com o que é observado.

No tocante à disciplina de sociologia, mais especificamente a participação dos professores no processo, percebemos a ausência de professores dessa disciplina no processo de construção do Referencial para a disciplina. Como consequência o grupo que compôs/representou a disciplina de sociologia foi formado por quatro docentes, dois deles graduados em Ciências Sociais e os demais graduados em Pedagogia e História, destes, três eram efetivos.

Através do acompanhamento das reuniões, indo para além dos discursos dos gestores, pudemos observar as dificuldades de articulação entre a Secretaria de Educação e as escolas, mas que também era acompanhada por boicotes às tentativas elaboradas pelos gestores. Dois dos docentes que participaram da pesquisa se recusam a participar das formações promovidas pela Secretaria, e eles apontam que os demais docentes da escola em que trabalham também se recusam a participar das formações. Essa ausência de professores também foi recorrente na fase atual da Reforma Curricular - a implantação -, de 13 Gerência Regional de Educação (GERE), somente 3 foram representadas através dos Formadores Estaduais ${ }^{10}$ de Sociologia.

Apesar de haver também uma baixa participação no caso de outras disciplinas, acreditamos que o fato de haver uma vasta predominância de professores com outras formações lecionando Sociologia, recorrentemente para fins de complementação de carga horária, pesa na participação dos docentes nessas atividades.

A pesquisa de campo junto aos momentos chaves de discussão em alguns momentos foi dificultada, já que não tínhamos acesso a todas as reuniões, o que se deve

\footnotetext{
${ }^{9}$ A equipe que constituía a GEORC, nesse momento, contava com quatro técnicos: dois pedagogos e dois agentes com graduação em Letras (FERREIRA, 2015, p. 93).

${ }^{10} \mathrm{O}$ formador regional é o agente que temo papel de multiplicador, pois receberá a formação do formador estadual e formará o professor, ele é o multiplicador.
} 
ao fato de que ao lidarmos com o âmbito das políticas públicas estamos nos voltando também para uma realidade permeada por múltiplos interesses, especialmente nesse contexto no qual havia claramente concepções em disputas com relação à forma como a reforma deveria ser conduzida, o próprio esvaziamento nas reuniões pode refletir uma discordância por parte dos docentes com relação à forma como o processo estava ocorrendo. Todavia, apenas a análise documental, ou mesmo apenas as entrevistas não teriam nos possibilitado enxergar do mesmo modo como se deu a reforma do currículo de Sociologia no Estado, pois foi a partir da participação nas reuniões, apenas as públicas, que pudemos perceber o hiato entre as propostas provindas do Estado e os interesses dos docentes, e de como os acordos eram estabelecidos na prática, ou, por vezes, como que a ação dos docentes, por meio do boicote às reuniões e às formações, também possuía implicações sobre a realidade analisada.

\section{Pesquisando com Professores de Sociologia}

A segunda pesquisa apresentada aqui ainda está em curso, de modo que as questões trazidas assentam-se nos dados preliminares obtidos até o momento, outros desafios para a pesquisa podem surgir em outros momentos, o que poderá ser objeto de outro trabalho.

Reconhecemos aqui que desafios encontrados no desenvolvimento do trabalho de campo podem estar relacionados à dificuldade de acesso ao campo em si, à dificuldade de acesso às informações ou, até mesmo, a dificuldades epistemológicas e tentativas infrutíferas de garantir a tão esperada neutralidade por parte tanto do pesquisador quanto das fontes de informações (SÁEZ, 2013).

A pesquisa a qual nos referimos aqui tem como objetivo compreender as constituições sociais e culturais, bem como as trajetórias e a formação dos professores de sociologia que atuam na rede estadual de ensino em Florianópolis, de forma a analisar como as disposições sociais incorporadas se relacionam com sua prática pedagógica. Para isso foram realizadas inicialmente entrevistas semiestruturadas, na forma de diálogos abertos, visando analisar e compreender a interação entre as experiências pessoais e profissionais dos professores ${ }^{11}$.

11 Trata-se da primeira etapa da pesquisa, considerando que também realizaremos etnografias multisituadas junto aos professores entrevistados, porém no espaço da sala de aula. 
A pesquisa teve início em meados de Agosto de 2015. O acesso às informações sobre a formação dos professores de sociologia que atuam na rede estadual, bem como a quantidade de professores de sociologia presentes em cada escola, foi, sem dúvida, a primeira dificuldade encontrada. Quando iniciamos a busca sobre a formação dos professores para realizar as entrevistas não encontramos fontes ou bases de dados que poderiam fornecer essas informações e, sendo assim, optamos por ligar para as escolas ou visitá-las sem aviso prévio, já que muitas vezes as ligações foram improdutivas. Obviamente que cada escola possui um funcionamento próprio que muitas vezes difere da ideia mais comum de uma possível institucionalização e padronização escolar, por parte do Estado, podemos compreender com isso que o sistema de ensino é único, porém as escolas são plurais. Ou ainda para pensarmos a partir das categorias da Sociologia e Antropologia da Educação, há inúmeras formas de "cultura da escola", ainda que haja uma "cultura escolar", por assim dizer mais geral, que permeia os hábitos rotineiros da instituição escolar moderna.

Dentro da estrutura da Secretaria de Educação de Santa Catarina, a Gerência de Educação (GERED) de Florianópolis seria o único órgão que poderia contribuir conosco em relação a informações relacionadas à formação dos professores. Contudo, a GERED estava passando por uma reorganização e estava também no processo de contratação dos professores, fator que postergou o nosso acesso a informações e nos obrigou, para que o cronograma da pesquisa fosse cumprido, a visitar as escolas mesmo que nossa procura não obtivesse sucesso. Além disso, as próprias escolas de Florianópolis estavam realizando mudanças no cadastro telefônico, o que dificultou o contato com muitas delas.

Aqui se faz pertinente pontuar que a pesquisa em campo escolar precisa estar consonante às agendas das escolas, ao contrário, torna-se bastante difícil o acesso nas mesmas, principalmente em períodos conturbados, como por exemplo, inícios e finais de semestre, quando reuniões pedagógicas, troca de professores, provas finais podem atrapalhar o acesso do pesquisador. Nesta pesquisa, o contato com os professores se realizou no final do semestre, exigindo assim uma negociação de horários de encontros, que atrapalhassem minimamente o andamento da escola e o fechamento do semestre. Como destaca Tura (2011, p. 192):

O pesquisador chega à escola. É o primeiro momento de contato com o seu campo de trabalho. Um primeiro momento que já foi antecedido 
por muitos outros, relacionados com as decisões em torno da investigação, da construção do objeto de estudo e do projeto de pesquisa. Seguiram-se a isso os contatos com as instâncias regionais e centrais da administração da educação escolar para obter as informações necessárias e a autorização para a entrada na escola. (...) Há espaços onde é nítido o cerceamento à entrada do pesquisador, o que é, muitas vezes, acompanhado da alegação de anteriores experiências negativas com a presença de estranhos no colégio.

Trata-se, portanto, de uma etapa delicada, pois de fato a presença de pesquisadores implica na existência de um "corpo estranho" inserido em uma determinada rotina. Durante as tentativas de visitação das escolas em busca dos professores de sociologia nos deparamos com algumas dificuldades de acesso a elas como, por exemplo, o requerimento por parte da secretária de uma das escolas de uma carta de apresentação do coordenador da pesquisa, para que a visita dos bolsistas pudesse ficar registrada. Apesar dessas dificuldades obtivemos sucesso em realizar as entrevistas com os professores que lecionam sociologia e eram formados em Ciências Sociais, portanto, habilitados para a docência nessa disciplina. Nessa etapa acessamos quatro diferentes escolas.

Não houve dificuldade de acesso aos professores após a visitação das escolas e nem empecilhos por parte dos docentes no que diz respeito a serem entrevistados. Contudo, nos deixando com o comum desconforto da entrada em campo, ou seja, do conquistar constante que o trabalho etnográfico exige (ROCKWELL, 2009), principalmente quando os agentes da pesquisa são professores de escolas públicas, que, mesmo com jornadas de trabalho extensas e cansativas, ainda disponibilizam tempo para conceder a entrevista, muitas vezes entre os horários de aula, em pequenas pausas durante a aula e reuniões pedagógicas. Devido a tanto, as entrevistas foram realizadas no próprio espaço da escola.

Como aponta Sáez (2013, p. 140): “(...) um trabalho de campo não passa de um trâmite burocrático se não oferece ao pesquisador um mergulho profundo naquilo que ele foi pesquisar". É evidente que levamos em conta tanto os limites externos como os limites internos durante o desenvolvimento da pesquisa, considerando os limites éticos e a impossibilidade de revelar alguns dados sobre as constituições pessoais dos professores entrevistados. Entretanto, apesar desses entraves já esperados por nós, nos deparamos durante as entrevistas com o que, talvez, podemos considerar o maior desafio encontrado durante a realização de nosso trabalho empírico: o discurso dos professores. 
De modo mais específico encontramos dificuldades epistemológicas ao entrevistarmos os professores de sociologia que eram formados em Ciências Sociais. Assim, ao entrevistarmos os professores habilitados para lecionar sociologia, ficou evidente que devido ao fato deles possuírem uma formação semelhante a nossa, assim como a aproximação relativa ao universo da pesquisa e das análises sociológicas e antropológicas, eles apresentavam certos discursos prontos. Em uma situação em que tanto o pesquisador quanto o sujeito de pesquisa possuem uma "língua comum", uma entrevista que deveria funcionar como um diálogo aberto, ocorrendo um "encontro etnográfico" (OLIVEIRA R. C., 2006), entretanto, a partir da capacidade de mobilização das mesmas categorias de pensamento por parte de pesquisador e sujeito de pesquisa, o que pudemos verificar é que se torna ainda mais difícil a "ruptura epistemológica” (BOURDIEU, CHAMBOREDON, PASSERON, 2004).

A dificuldade de obter informações além de um discurso pronto de alguém formado na área das Ciências Sociais, também se relaciona com a forma de aproximação utilizada por nós pesquisadores. Aqui cabe a análise que Rockwell (2009) faz a partir dos dilemas encontrados quando falamos da sinceridade durante o trabalho de campo e as estratégias utilizadas por pesquisadores na hora de obter informações pertinentes para a pesquisa. Segundo ela, uma coisa não necessariamente subtrai a outra, e esse exercício ético também faz parte da busca por um conhecimento construído mais localmente.

Obviamente que tais questões não nos impossibilita a realização do trabalho de campo, sem embargo, devemos reconhecer que o processo de pesquisa com uma realidade familiar - que envolve um sistema de ensino no qual fomos educados, bem como o diálogo com pares (outros cientistas sociais) - traz desafios bastante singulares. Para Velho (1987), é possível ao pesquisador transcender, em determinados momentos, suas limitações de origem e ver o familiar não como exótico, mas como uma realidade bem mais complexa. Ainda segundo o autor "O processo de estranhar o familiar tornase possível quando somos capazes de confrontar intelectualmente, e mesmo emocionalmente, diferentes versões e interpretações existentes a respeito de fatos, situações." (Idem, p. 130).

\section{Considerações Finais}


Dentro dos limites existentes, buscamos nesse breve trabalho trazer alguma contribuição ao debate sobre o Ensino de Sociologia na realidade brasileira, o que foi realizado tanto através de um balanço mais geral em acerca da produção que temos produzida no nível da pós-graduação sobre o tema, como também por meio de algumas indicações acerca dos desafios encontrados no processo de desenvolvimento de pesquisas empíricas, mais especificamente etnografias, envolvendo esta temática.

Ainda que tenhamos tomado como fio condutor pesquisas realizadas a partir de contextos sensivelmente distintos, e com focos também distintos, ficou-nos evidente que alguns desafios ao trabalho de campo nessa seara parecem demarcar um continuum, como a dificuldade de acesso a determinados dados por parte das secretarias de educação, que podem ser reflexo de certa descontinuidade em termos de políticas educacionais, como também podem indicar particularidades com relação ao Ensino de Sociologia, considerando sua reintrodução recente no currículo em termos nacionais, o que apontaria para uma realidade formada por um corpo docente ainda relativamente instável, salvo as particularidades regionais e locais, que inclui também a reintrodução da disciplina em período anterior à lei $\mathrm{n}^{\circ} 11.684 / 08$.

O contato direto com as escolas e com os professores demanda também um esforço metodológico e epistemológico considerável por parte dos pesquisadores, tendo em vista a complexidade que envolve investigar uma comunidade de pares. $\mathrm{O}$ encontro etnográfico realiza-se não com um outro substancialmente distinto com o qual não compartilhamos do mesmo horizonte simbólico, mas sim com um outro com o qual nos identificamos, em alguns casos isso ocorre de forma ainda mais explícita quando se trata de professores que atuam ou atuaram na Educação Básica pesquisando outros professores, dado que precisa ser melhor problematizado epistemologicamente nas pesquisas.

Acreditamos, portanto, que as pesquisas de campo na área do Ensino de Sociologia podem trazer avanços significativos para o debate em curso, a triangulação dos dados, como apontaram Sarmento (2011) e Woods (1999) podem nos levar a perceber questões ainda pouco exploradas pela literatura disponível. A observação do cotidiano do Ensino de Sociologia pode nos possibilitar perceber como que essa disciplina de fato se operacionaliza nas escolas, em suma, poderia nos levar a conhecer de fato que Sociologia temos nas escolas. 


\section{Referências}

BARTH, Fredrik. O guru, o iniciador e outras variações antropológicas. Rio de Janeiro: Contra Capa Livraria, 2000.

BEAUD, Séphane; WEBER, Florence. Guia para a Pesquisa de Campo: produzir e analisar dados etnográficos. Petrópolis: Vozes, 2007.

BOURDIEU, Pierre. Coisas ditas. São Paulo: Brasiliense, 2004.

BOURDIEU, Pierre; CHAMBOREDON, Jean-Claude; PASSERON, Jean-Claude. O Ofício do Sociólogo: metodologia da pesquisa na sociologia. Petrópolis: Vozes, 2004.

BRASIL. Lei $\mathrm{n}^{\circ} 11.684$, de 2 de junho de 2008. Altera o art. 36 da lei $\mathrm{n}^{\circ}$ 9.394, de 20 de dezembro de 1996, que estabelece as diretrizes e bases da educação nacional, para incluir a Filosofia e a Sociologia como disciplinas obrigatórias nos currículos do ensino médio. Diário Oficial da União, Brasília, 3 de junho de 2008.

CAREGNATO, Célia. E.; CORDEIRO, Victoria C. Campo cientíëco-acadêmico e a disciplina de sociologia na escola. Educação \& Realidade, Porto Alegre, v. 39, n. 1, p. 3957, jan./mar. 2014.

FERREIRA, Vanessa R. A Construção dos Referenciais Curriculares de Sociologia em Alagoas. Dissertação/Mestrado em Educação, Centro de Educação, Universidade Federal de Alagoas. Maceió, 2015.

GUSMÃO, Neusa Maria Mendes. Trajetórias, prcalços e conquistas da antropologia da educação no Brasil. In: GUEDES, Simone Lahud; CIPINIUK, Tatiana Arnaud (Orgs.). Abordagens etnográficas sobre educação: adentrando os muros da escola. Niterói: Editora Alternativa, 2014, p. 13-24.

HANDFAS, Anita; MAÇAIRA, Júlia P. O estado da arte da produção científica sobre o ensino de sociologia na educação básica. BIB. Revista Brasileira de Informação Bibliográfica em Ciências Sociais, São Paulo, v.2, n. 74, 2014, p. 45-61.

MORAES, Amaury C. Ensino de Sociologia: periodização e campanha pela obrigatoriedade. Cadernos CEDES, Campinas, v. 31, nº 85, 2011, p. 359-382.

MARTINS, Carlos B.; WEBER, Silke. Sociologia da Educação: democratização e cidadania. In: MARTINS, Carlos B; MARTINS, Heloisa H. T. S. Horizontes das Ciências Sociais: Sociologia. São Paulo: ANPOCS, 2010, p. 131-201.

MEUCCI, Simone. A institucionalização da sociologia no Brasil: primeiros manuais e cursos. Dissertação/Mestrado em Sociologia, Instituto de Filosofia e Ciências Humanas, Universidade Estadual de Campinas. Campinas, 2000.

NEVES, Clarissa B. E. Estudos Sociológicos sobre Educação no Brasil. In: MICELI, Sergio (Org.). O que ler na ciência social brasileira 1970-2002: Sociologia. São Paulo; Brasília: Editora Sumaré; CAPES, v. IV, 2002, p. 351-437.

OLIVEIRA, Amurabi. Por que Etnografia no sentido Estrito e não Estudos do Tipo Etnográfico em Educação?. Revista FAEEBA, v. 22, 40, p. 69-82, 2013. 
Sobre o Lugar da Educação na Antropologia Brasileira. Temas em Educação, v. 24, 1, p. 32-39, 2015a.

. Um balanço sobre o campo do ensino de sociologia no Brasil. Em Tese, v. 12, n. 2, p. 6-16, 2015 b.

OLIVEIRA, Amurabi; CIGALES, Marcelo Pinheiro. A Pesquisa como Princípio Pedagógico no Ensino de Sociologia: uma análise a partir dos livros selecionados no PNLD 2015. Ciências Sociais Unisinos, v. 15, p. 279-289, 2015.

OLIVEIRA, Amurabi; FERREIRA, Vanessa do Rêgo; SILVA, Claudovan Freire. Percurso e Singularidades do Ensino de Sociologia em Alagoas. Saberes em Perspectivas (UESB), Jequié: BA, vol. 4, no 8, p. 11-34, 2014.

OLIVEIRA, Amurabi; SILVA, Camila Ferreira. Mapeamento da Sociologia da Educação no Brasil: análise de um campo em construção. Atos de Pesquisa em Educação, v. 9, n. 2, p. 289-315, 2014.

OLIVEIRA, Roberto Cardoso. O trabalho do antropólogo. São Paulo: Editora UNESP, 2006.

ROCKWELL, Elsie. La experiencia etnografica: historia y cultura en los procesos educativos. Buenos Aires: Paidós, 2009.

SÁEZ, Oscar. Esse obscuro objeto da pesquisa. Ilha da Santa Catarina, 2013.

SANTOS, Mario Bispo. A Sociologia no Ensino Médio: o que pensam os professores da rede pública do Distrito Federal. Dissertação/Mestrado em Sociologia, Instituto de Ciências Sociais, Universidade de Brasília. Brasília, 2002.

SARMENTO, Manuel Jacinto. O estudo de caso etnográfico em educação. In: ZAGO, Nadir; CARVALHO, Marília Pinto; VILELA, Rita Amélia (Orgs.) Itinerários de pesquisa: perspectivas qualitativas da sociologia da educação. Rio de Janeiro: Lamparina, 2011. p. 137-179.

SCHWEIG, Graziela Ramos. Aprendizagem e ciência no ensino de sociologia: um olhar desde a antropologia. Tese/Doutorado em Antropologia Social, Instituto de Filosofia e Ciências Humanas, Universidade Federal do Rio Grande do Sul. Porto Alegre, 2015.

TAKAGI, Cassiana Tiemi Tedesco. Formação de Professores de Sociologia do Ensino Médio: um estudo sobre o currículo do curso de ciências sociais da Universidade de São Paulo. Tese/Doutorado em Educação, Faculdade de Educação, Universidade de São Paulo, São Paulo, 2013.

TURA, Maria de Lourdes Rangel. A observação do cotidiano escolar. ZAGO, Nadir; CARVALHO, Marília Pinto; VILELA, Rita Amélia (Orgs.) Itinerários de pesquisa: perspectivas qualitativas da sociologia da educação. Rio de Janeiro: Lamparina, 2011. p. 183-206.

VALENTE, Ana Lúcia. Usos e abusos da antropologia na pesquisa educacional. Proposições, v. 7, n. 20, p. 54-64, 1996. 
VELHO, Gilberto. Individualismo e cultura: notas para uma antropologia da sociedade contemporânea. Rio de Janeiro: Jorge Zahar Ed., 1987.

WOODS, Peter. Investigar a ensinar. Porto: Porto Editora, 1999. 